\title{
Common running musculoskeletal injuries among recreational half-marathon runners in KwaZulu-Natal
}

\author{
T J Ellapen, PhD; S Satyendra, BSps (Hons) (Biokinetics); J Morris, BSps (Hons) (Biokinetics); H J van Heerden, DPhil \\ Department of Sport Science, School of Physiotherapy, Sport Science and Optometry, University of KwaZulu-Natal, Durban, South Africa
}

Corresponding author: T J Ellapen (tellapen1@yahoo.com)

\begin{abstract}
Objective. To document the prevalence and nature of running-related musculoskeletal injuries among recreational half-marathon runners over a 12-month period (1 July 2011 - 31 June 2012).

Methods. Data were collected from runners $(N=200)$ who officially ran half-marathon road races during February - June 2012. Runners, whose participation in the study was dependent on voluntary informed consent, were required to complete a self-report questionnaire probing the prevalence and nature of running musculoskeletal injuries in the 12 months preceding recruitment. Probability was set at $p \leq 0.05$.

Results. One hundred and eighty (90\%) runners reported sustaining musculoskeletal injuries $(p<0.001)$. The anatomical site most vulnerable to injury was the knee (26\%), followed by the tibia/fibula (22\%) and the lower back/hip $(16 \%)(p<0.001)$. The intrinsic factors predisposing runners to musculoskeletal injuries were deviant quadriceps and hip flexion angles $(p \leq 0.05)$.

Conclusion. Recreational runners in our cohort sustained a high prevalence of knee, tibia/fibula and lower back/hip injuries.
\end{abstract}

S Afr J SM 2013;25(2):39-43. DOI:10.7196/SAJSM.360

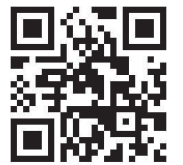

Predisposing factors contributing to musculoskeletal running injuries include poor training habits, inadequate rehabilitation of previous injuries, high weekly mileage, incorrect shoes and muscle imbalances. ${ }^{[1-4]}$ Studies have identified the knee as the anatomical site most vulnerable to running-related musculoskeletal injury, followed by the ankle. ${ }^{[1-4]}$ Intrinsic factors such as deviant quadriceps angles (Q-angles), genu varum, genu valgum, rear foot varus and rear foot valgus have been associated with vulnerability to knee and ankle injuries. ${ }^{[1,5,6]}$ There is controversy concerning the relationship between deviant Q-angles and knee injuries among runners. ${ }^{[7,8]}$ Lun et al. ${ }^{[7]}$ and Messier et al. ${ }^{[8]}$ have reported that deviant Q-angles do not play a significant role in the predisposition towards knee injuries, while others ${ }^{[6,9,10]}$ advocate that large Q-angles are a positive risk factor for knee injuries among runners. Only one South African study has investigated the association of deviant Q-angles and knee injuries among runners. ${ }^{[6]}$ There is a need for further epidemiological investigations to determine intrinsic risk factors that predispose runners to musculoskeletal injuries. We aimed to compare training habits, Q-angles and hip flexion between runners who did, and those who did not incur running injuries in the 12 months preceding study recruitment.

\section{Methods}

\section{Participants}

We performed a retrospective and descriptive study of the prevalence of running-related musculoskeletal injuries in the preceding 12 months among 200 runners, aged 18 - 57 years, from different athletic clubs affiliated to the KwaZulu-Natal Athletic Association. Ethical approval for the study was obtained from the School of Health Science
Research Committee, University of KwaZulu-Natal. The cohort regularly participated in half-marathons $(21.1 \mathrm{~km})$, with an average road-running history of 12.2 years (standard deviation $(\mathrm{SD}) \pm 1.4$ ). Runners participated in the study by signing voluntary informed consent. Their personal details, training histories and running-related injuries were obtained using a self-report, validated, musculoskeletal injury questionnaire adapted from Van Heerden. ${ }^{[1]}$

\section{Questionnaire}

Participants were requested to indicate only running-related musculoskeletal injuries experienced as a sensation of distress or agony, and which prevented them from physical activity for a minimum of 24 hours (adapted from Van Herdeen ${ }^{[11]}$ ). In the self-report questionnaire, the running-related musculoskeletal injuries were further investigated according to anatomical site of musculoskeletal pain, intensity/severity of pain (according to the Kee and $\mathrm{Seo}^{[12]}$ pain-rating scale) and symptoms (dull aching, discomfort, sharp, pins and needles, numbness, burning and radiating). ${ }^{[12]}$ Hagglund et al. ${ }^{[13]}$ reported that the fundamental problem concerning international epidemiological sport investigations is the inconsistent definition of musculoskeletal injury. ${ }^{[13]}$ The authors proposed that the prevalence of musculoskeletal injury can be established, if the following is documented: anatomical site, sustained type and severity of pain measured by a validated pain-rating scale. ${ }^{[13]}$ Pain was employed in the questionnaire because it is a discernible symptom of musculoskeletal injury. The questionnaire also contained a training history section that attempted to determine whether weekly running mileage was a contributing factor to musculoskeletal injury. Training history was determined by recording training schedules according to the frequency of training sessions per week, the distance run during 
each training session, and training type (slow long distance, tempo, time trial, intervals and recovery).

\section{Anthropometric measurements}

In addition to information probed by the questionnaire, the following anthropometric measurements were recorded: body mass, stature, Q-angle and hip flexion (Thomas test). The objective was to determine whether a significant relationship existed between these intrinsic factors and musculoskeletal injury.

We measured the Q-angle according to Livingston and Spaulding. ${ }^{[14]}$ The runner lay supine on the plinth with foot in neutral position. The anterior superior iliac spine (ASIS), the centre of the patella and the tibial tuberosity, were marked using a pen. The centre of the goniometer was placed on the centre of the patella (found by the intersecting width and length lines). The stationary arm of the goniometer was aligned with the ASIS and the movable arm was aligned with the tibial tuberosity. A third vertical line that extended from the tibial tuberosity along the femur allowed the formation of an angle. Three readings were taken for each runner by the same investigator (to ensure test-re-test reliability).

The Thomas test measured the tightness of the hip flexors (rectus femoris and iliopsoas) according to Starke and Ryan. ${ }^{[15]}$ The runner lay supine on the plinth with their knees bent and lower limb hanging over the edge. The runner's posterior thighs lay against the surface of the plinth. The greater trochanter and lateral femoral condyle of the ipsilateral leg were identified and a line was drawn between these two landmarks. The first clinician aligned the stationary arm of the goniometer onto the greater trochanter and the line drawn of the ipsilateral thigh. The second clinician passively flexed the contralateral hip bringing the knee to the chest (contra-lateral hip and knee flexed). The movable arm of the goniometer was then aligned to the drawn line of the ipsilateral thigh as the contra-lateral hip was flexed. The angle created by the intersection of the stationary and movable lines was measured. Three readings were taken for each subject by the same investigator (to ensure test-re-test reliability).

\section{Statistical analysis}

We used descriptive statistics including mode, mean, frequency and percentages, and inferential statistics comprising Levene's test, chisquare and $t$-tests. The Levene's test was used to assess the homogeneity variance that revealed unequal variance $(p<0.05)$. A two-tailed $t$-test adjusted for unequal variance was employed to assess the statistical comparative significance of the injured v. non-injured runners. The probability level was set at $p<0.05$.
Results

The cohort $(N=200)$ comprised 120 males $(60 \%)$ and 80 females $(40 \%)$, of white (50\%), Indian (33\%), African (12\%) and coloured (6\%) race (Table 1); and 180 (90\%) participants experienced a collective total of 294 running injuries $(p<0.001)$. Male $(n=107)$ and female $(n=73)$ runners experienced 178 and 116 running injuries, respectively. The point prevalence of the anatomical site of these injuries is presented in Table 2.

The Kee and Seo ${ }^{[12]}$ pain-rating scale $(1=$ uncomfortable, $2=$ mild, $3=$ moderate, $4=$ severe and $5=$ worst experienced) was employed to subjectively rate the intensity of running-related musculoskeletal pain. Among those who experienced running injury, a score of 3 (moderate pain intensity) was rated the most prevalent $(42.46 \%)$, followed by a score of 2 (32.4\%), 4 (11\%), $1(8 \%)$ and $5(7 \%)(p<0.01)$. The most common symptoms associated with running injuries were dull aching (43\%), followed by sharp (20\%), discomfort (13\%), burning (10\%), radiating (4\%), pins and needles (4\%), swelling (3\%) and numbness (3\%) $(p<0.01)$. The anthropometric measurements of the runners are presented in Tables 5 and 6 .

Runners addressed specific components of their running conditioning on set weekdays, thereby prescribing a rigid weekly training schedule and enabling us to monitor their training habits (Tables 3 and 4). In addition to the prerequisite running training, participants were required to report whether they performed any cross-training. The female runners ran an average of 11.3 months per year $(S D \pm 0.5$ ) including 4.4 sessions per week ( $\mathrm{SD} \pm 1.4$ ), while the male runners ran an average of 11.0 months per year ( $\mathrm{SD} \pm 0.6$ ) including 4.0 sessions per week ( $\mathrm{SD} \pm 1.3$ ). Regarding cross-training activities, 48 female runners engaged in resistance strength training $(n=30)$ and swimming $(n=18)$, while 58 male runners engaged in resistance strength training $(n=37)$, swimming $(n=14)$, action cricket $(n=4)$ and touch rugby $(n=2)$. Male and female runners who cross-trained also sustained running injuries.

The comparative statistical analyses of the training mileage of noninjured v. injured runners revealed no statistical significance $(p>0.05)$; injured female runners completed $499 \mathrm{~km}$, while non-injured females completed $509 \mathrm{~km}$ during the 12-month period $(p>0.05)$. During this time, the injured females sustained a total of 116 injuries. Both injured and non-injured male runners completed $506 \mathrm{~km}$ during the 12 -month period $(p>0.05)$, with the injured male runners sustaining a total 178 injuries.

\section{Discussion}

Among the 200 runners surveyed, 180 (90\%) experienced running-related musculoskeletal injury within the preceding 12

Table 1. Participant demographics $(N=200)$

\begin{tabular}{|c|c|c|}
\hline Variables & Males $(N=120)$ & Females $(N=80)$ \\
\hline Age (years), mean $( \pm \mathrm{SD})$ & $44.3( \pm 12.7)$ & $42.9( \pm 12.5)$ \\
\hline Body mass $(\mathrm{kg})$, mean $( \pm \mathrm{SD})$ & $73.6( \pm 12.1)$ & $60.7( \pm 7.8)$ \\
\hline Stature $(\mathrm{m})$, mean $( \pm \mathrm{SD})$ & $1.73( \pm 0.08)$ & $1.6( \pm 0.07)$ \\
\hline BMI $\left(\mathrm{kg} / \mathrm{m}^{2}\right)$, mean $( \pm \mathrm{SD})$ & $24.3( \pm 3.4)$ & $22.7( \pm 3.07)$ \\
\hline Running experience (years), mean $( \pm S D)$ & $13.2( \pm 10.5)$ & $11.2( \pm 9.2)$ \\
\hline
\end{tabular}


Table 2. Percentage reflection of the point prevalence of musculoskeletal injury at various anatomical sites ${ }^{*}$

\begin{tabular}{|c|c|c|c|}
\hline Anatomical site & $\begin{array}{l}\text { Males }(N=107) \\
\%\end{array}$ & $\begin{array}{l}\text { Females }(N=73) \\
\%\end{array}$ & $\begin{array}{l}\text { Mean } \\
\%\end{array}$ \\
\hline Neck & 1.7 & 0.9 & 1.3 \\
\hline Shoulder & 1.1 & 1.7 & 1.4 \\
\hline Elbow & 0.6 & 0.0 & 0.3 \\
\hline Hand & 1.1 & 0.9 & 1.0 \\
\hline Lower back/hip & 15.2 & 16.4 & 15.8 \\
\hline Thigh & 15.7 & 11.2 & 13.5 \\
\hline Knee & 27.0 & 25.9 & 26.4 \\
\hline Tibia/fibula & 20.2 & 23.3 & 21.7 \\
\hline Ankle & 12.4 & 7.8 & 10.1 \\
\hline Foot & 5.1 & 12.1 & 8.6 \\
\hline
\end{tabular}

Table 3. Comparative analyses of the mean weekly run mileage of injured v. non-injured male runners $(N=120)$

\begin{tabular}{llll}
\hline Training components & Injured $(\boldsymbol{N}=\mathbf{1 0 7})$ & Non-injured $(\boldsymbol{N}=\mathbf{1 3})$ & $\boldsymbol{p}$-value \\
\hline Long slow distance $(\mathrm{km})$, mean $( \pm \mathrm{SD})$ & $21.6( \pm 10.36)$ & $21.3( \pm 8.08)$ & $>0.05$ \\
Tempo $(\mathrm{km})$, mean $( \pm \mathrm{SD})$ & $9.6( \pm 4.5)$ & $8.0( \pm 3.4)$ & $>0.05$ \\
Time trial $(\mathrm{km})$, mean $( \pm \mathrm{SD})$ & $6.0( \pm 2.0)$ & $7.7( \pm 1.6)$ & $<0.05$ \\
Hill $(\mathrm{km})$, mean $( \pm \mathrm{SD})$ & $7.1( \pm 4.6)$ & $6.0( \pm 5.2)$ & $>0.05$ \\
Recovery $(\mathrm{km})$, mean $( \pm \mathrm{SD})$ & $8.8( \pm 5.8)$ & $10.1( \pm 5.3)$ & $>0.05$ \\
Weekly mileage $(\mathrm{km})$, mean $( \pm \mathrm{SD})$ & $10.6( \pm 6.2)$ & $10.6( \pm 6.1)$ & $>0.05$
\end{tabular}

$\mathrm{SD}=$ standard deviation

Table 4. Comparative analyses of the mean weekly run mileage of injured $v$. non-injured female runners $(N=80)$

\begin{tabular}{llll}
\hline Training components & Injured $(\boldsymbol{N = 1 0 7})$ & Non-injured $(\mathbf{N}=\mathbf{1 3})$ & $\boldsymbol{p}$-value \\
\hline Long slow distance $(\mathrm{km})$, mean $( \pm \mathrm{SD})$ & $18.4( \pm 7.2)$ & $17.5( \pm 3.1)$ & $>0.05$ \\
Time trial $(\mathrm{km})$, mean $( \pm \mathrm{SD})$ & $4.6( \pm 1.3)$ & $5.1( \pm 1.9)$ & $>0.05$ \\
Recovery $(\mathrm{km})$, mean $( \pm \mathrm{SD})$ & $7.6( \pm 3.1)$ & $8.8( \pm 1.3)$ & $>0.05$ \\
Weekly mileage $(\mathrm{km})$, mean $( \pm \mathrm{SD})$ & $10.2( \pm 7.2)$ & $10.4( \pm 6.3)$ & $>0.05$ \\
$\mathrm{SD}=$ standard deviation. & & &
\end{tabular}

Table 5. Comparative analyses of the mean Q-angles of runners with knee injuries v. those with non-knee injuries $(N=200)$

\begin{tabular}{|c|c|c|c|}
\hline Q-angle & Non-injured & Injured & $p$-value \\
\hline Male & $n=72$ & $n=48$ & \\
\hline Right Q-angle $\left({ }^{\circ}\right)$, mean $( \pm \mathrm{SD})$ & $9.1( \pm 1.2)$ & $10.9( \pm 3.2)$ & $<0.01$ \\
\hline Left Q-angle $\left({ }^{\circ}\right)$, mean $( \pm \mathrm{SD})$ & $9.6( \pm 1.3)$ & $10.4( \pm 2.1)$ & $<0.05$ \\
\hline Female & $n=50$ & $n=30$ & \\
\hline Right Q-angle $\left({ }^{\circ}\right)$, mean $( \pm \mathrm{SD})$ & $12.4( \pm 1.9)$ & $13.4( \pm 2.4)$ & $>0.05$ \\
\hline Left Q-angle $\left({ }^{\circ}\right)$, mean $( \pm \mathrm{SD})$ & $12.7( \pm 1.7)$ & $14.2( \pm 2.9)$ & $<0.01$ \\
\hline
\end{tabular}

months $(p<0.0001)$, in line with previous literature..$^{[2,4,16]}$ Statistical interrogation of the data revealed that the lower extremities (lower back/hip, thigh, knee, tibia/fibula, ankle and foot) experienced the most musculoskeletal injuries (96\%), followed by the upper extremities (shoulder, elbow and hand) (3\%) and neck (1\%) $(p<0.001)$. Marti et al. ${ }^{[3]}$ and Van Mechelen ${ }^{[4]}$ reported a prevalence of musculoskeletal running injuries in the lower extremities of $70 \%$ and $80 \%$, respectively. ${ }^{[3,4]}$ Powell ${ }^{[5]}$ and Van Gent et al ${ }^{[16]}$ reported that 
Table 6. Comparative analyses of the mean hip flexion angles (Thomas test) of runners with lower-back/hip injuries v. those with non-lower-back/hip injuries $(N=200)$

\begin{tabular}{llll}
\hline Hip flexion angle & Non-injured & Injured & $p$-value \\
\hline Males & $n=93$ & $n=27$ & $>0.05$ \\
Right hip $\left({ }^{\circ}\right)$, mean $( \pm \mathrm{SD})$ & $7.9( \pm 2.9)$ & $8.03( \pm 2.2)$ & $>0.05$ \\
Left hip $\left({ }^{\circ}\right)$, mean $( \pm \mathrm{SD})$ & $7.6( \pm 2.9)$ & $7.9( \pm 2.4)$ & \\
Females & $n=61$ & $n=19$ & $<0.01$ \\
$\quad$ Right hip $\left(^{\circ}\right)$, mean $( \pm \mathrm{SD})$ & $6.6( \pm 1.7)$ & $12.6( \pm 2.2)$ & $<0.01$
\end{tabular}

a widespread predisposing factor responsible for lower extremity musculoskeletal injury among runners is a high running weekly mileage. However, the comparative statistical analyses of the run training mileage of the non-injured v. injured runners revealed no statistical significance in our study $(p>0.05)$. This suggests that the running mileage was not a contributing factor that predisposed the runners to musculoskeletal injury.

The knee was the most susceptible anatomical site to musculoskeletal injury $(p<0.001)$, in agreement with previous findings. ${ }^{[6,16]}$ Puckree et al. ${ }^{[6]}$ documented that the presence of deviant Q-angles among male runners predisposes them to musculoskeletal knee injury. The Q-angle is an indicator of the muscle symmetry of the quadriceps femoris muscle surrounding the knee. Larger Q-angles increase the compressive forces applied to the lateral facet of the patella, and increase the tensile forces on the medial patellar restraint (collectively producing musculoskeletal pain and discomfort).$^{[6,18]}$ Repetitive and prolonged stressing of the medial patellar restraint reduces its effectiveness against traction force of the lateral patellar restraint. This medial patellar restraint inefficiency results in lateral patella tracking, indicated by the abnormal Q-angle $(p<0.05)$, which precipitates the onset of patellar femoral pain syndrome. ${ }^{[14,17]}$ Consistent with Puckree et al. ${ }^{[6]}$ male runners in our cohort who sustained musculoskeletal knee injuries had larger deviant Q-angles, differing significantly from non-injured runners $(p<0.05)$. This suggests that $\mathrm{Q}$-angle deviation was a predisposing factor to musculoskeletal knee injuries among these male runners. To our knowledge, no published literature examines the association of knee injuries and Q-angles among females. In our study, the left Q-angle of female runners who sustained knee injuries was significantly greater than that of non-injured runners $(p<0.05)$, suggesting a stronger vastus lateralis than vastus medialis in the former.

The second-most vulnerable anatomical site to musculoskeletal injury was the tibia/fibula, supporting similar findings by Stergiou et al. ${ }^{[18]}$ who postulated that the excessive pronation of the subtalar joint increases the torsional forces up the tibia and fibula, producing injuries. This torsional force is a result of the ground reaction forces transferred to the plantar surface of the foot that changes the rear foot angle, which alters the amount of pronation at the subtalar joint and propagates increased torsional forces up the lower limb. ${ }^{[18]}$

The prevalence of lower back/hip injury among the runners $(p<0.001)$ was a unique finding with regard to previous running epidemiological investigations. Runners who sustained lower back/ hip injuries had greater hip flexion angles (as measured by the Thomas test) than non-injured runners. Furthermore, the hip flexion angles of female runners who sustained lower back/hip musculoskeletal injuries differed significantly from those of their non-injured counterparts $(p<0.01)$; there is no literature to explain this finding. It is postulated that the tight hip flexors produce an anterior pelvic tilt which alters the normal length tension relationship between the hip posterior rotators/extensors and anterior hip rotators/flexors. ${ }^{[19]}$ Prolonged anterior tilting of the pelvis shortens the iliopsoas and elongates the gluteal muscles; this asymmetry muscle development creates an abnormal force couple, facilitating muscle spasms in the hip flexors and strains in the hip extensors yielding symptoms of dull aching sensations. ${ }^{[19]}$

In our study, the most common symptoms associated with running injuries were dull aching (42.46\%), followed by sharp (20\%), discomfort (13\%), burning (10\%), radiating $(4 \%)$, pins and needles (4\%), swelling (3\%) and numbness (3\%). Mansfield and Neumann ${ }^{[19]}$ identified dull aching, sharp pain and discomfort sensations as muscle injury. The combination of dull aching, sharp and discomfort in our study suggests that the runners experienced a higher percentage of muscle injury (7\%). This, in combination with the data from the anatomical site of musculoskeletal pain, the severity of the musculoskeletal pain sustained and the identification of the type of pain sensation experienced indicated the prevalence of running musculoskeletal injuries.

\section{Conclusion}

Runners experienced a high prevalence of knee, lower back/hip and tibia/fibula musculoskeletal injuries, consistent with previous research findings. ${ }^{[5-10]}$ Knee and lower back/hip injuries have been associated with deviant Q-angles and tight hip flexors, respectively. The findings of this study can be best utilised if athletic coaches and runners take cognizance of them and seek professional help to alleviate the high prevalence of musculoskeletal injury, by engaging in rehabilitative and preventive exercises. In addition, runners should be educated on various ways to prevent injury by adhering to appropriate training regimens, alterations in running technique and appropriate foot wear selection. A limitation of our study was the recall bias of the retrospective reporting of musculoskeletal injury and training volumes. Future epidemiological running injury studies should be limited to smaller age ranges, as some older individuals may have had significantly different physiological and biomechanical capacities. The inclusion of the Thomas test added value to the findings of the intrinsic nature of the lower 
back/hip musculoskeletal injuries experienced by female runners. Future studies are required to validate our findings and to better understand the association of the mechanisms by which intrinsic factors predispose runners to musculoskeletal injuries.

\section{References}

1. Noakes T. The Lore of Running. 4th ed. Leeds, UK: Human Kinetics, 2001:973-1041.

2. Taimela S, Kujalo M, Oesteiman K. Intrinsic risk and athletic injuries. Sport Med 1990;9:205-218.

3. Marti B, Vader JP, Minder CE, Abelin T. On the epidemiology of running injuries. Am J Sport Med 1988;16:285-294.

4. Van Mechelen W. Running injuries: A review of the epidemiological literature. Sport Med 1992;14:320-335.

5. Powell KE. An epidemiological perspective on the cause of running injuries. Physician Sport Med 1986;14(6):100-108.

6. Puckree T, Govender A, Govender K, Naidoo P. The quadriceps angle and the incidence of knee injury in Indian long distance runners. South African Journal of Sports Medicine 2007;19(10):9-11.

7. Lun V, Meeuwisse WH, Stergiou P, Stefanyshyn D. Relation between running injury and static lower limb alignment in recreational runners. Br J Sport Med 2004;38:576580. [http://dx.doi.org/10.1136/bjsm.2003.005488]

8. Messier SP, Davis SE, Curl WW, Lowery RB, Pack RJ. Etiologic factors associated with patellofemoral pain in runners. Med Sci Sports Exerc 1991;23:1008-1015.
9. Ivkovic A, Franic M, Bolanic I, Pecina M. Overuse injuries in female athletes. Croet Med J 2007;48(6):767-778. [http://dx.doi.org/10.3325/cmj.2007.6.767]

10. Warvasz GR, McDermott AY. Patellofemoral pain syndrome (PFPS): A systematic review of anatomy and potential risk factors. Dyn Med 2008;7:9. [http://dx.doi. org/10.1186/1476-5918-7-9]

11. Van Heerden HJ. Pre-participation evaluation and identification of aetiological risk factors in epidemiology of sports injuries among youths. $\mathrm{PhD}$ thesis. Pretoria: University of Pretoria, 1996.

12. Kee D, Seo SR. Musculoskeletal disorders among nursing personnel in Korea. Int J Ind Erg 2007;37:207-212. [http://dx.doi.org/10.1016/j.ergon.2006.10.020]

13. Hagglund M, Walden M, Bahr R, Ekstrand J. Methods for epidemiological study of injuries to professional football players: Developing the UEFA model. Br J Sport Med 2005;39:340-346. [http://dx.doi.org/10.1136\%2Fbjsm.2005.018267]

14. Livingston LA, Spaulding SJ. Measuring of the quadriceps angle using standardized foot positions. J Athl Training 2002;37:252-255.

15. Starke C, Ryan FL. Evaluation of Orthopaedic and Athletic Injuries. 2nd ed. Philadelphia, USA: F A Davis Company, 2001:288-289.

16. Van Gent RN, Siem D, Van Middelkoop M, Van Os AG, Bierma-Zeinstra SMA, Koes BW. Incidence and determinates of lower extremity running injuries in long distance runners. A systemic review. Br J Sport Med 2007;41:469-480. [http://dx.doi. org/10.1136/bjsm.2006.033548]

17. Grelsamer GP, Weinstein CH. Applied biomechanics of the patella. Clin Orthop 2001;389:9-14.

18. Stergiuo N, Bates BT, Stanley LS. Asynchrony between subtalar and knee joint during running. Med Sci \& Sport Ex 1999;31(11):1645-1654.

19. Mansfield PJ, Neumann DA. Essential of Kinesiology for the Physical Therapist's Assistance. Mosby: Elsevier, 2008:227-268. 